\title{
Abdominal Aortic Aneurysm Presenting as Paraplegia: Case Report
}

\author{
P. T. Chatlani, BSc, MB, ChB, FRCS (Ed), FRCS, ${ }^{1}$ M. G. Van Dessel, \\ MB, BCh, BAO, BSC, ${ }^{1}$ K. R. Krishnan, MBBS, FRCS(Ed), ${ }^{2}$ G. A. \\ McLoughlin, MD, FRCS(Ed), FRCS ${ }^{1}$ \\ ${ }^{1}$ Royal Liverpool Hospital, Prescot Street, Liverpool, L7 8XP ${ }^{2}$ Director, Spinal \\ Injuries Unit, Promenade Hospital, Southport, UK.
}

\begin{abstract}
Summary
A 65-year-old man with a previously undiagnosed abdominal aortic aneurysm presented with acute paraplegia. Elective resection of the aneurysm was undertaken one week later. Following this, almost complete neurological recovery was regained by 11 months.
\end{abstract}

Key words: Aortic aneurysm; Paraplegia; Spinal artery thrombosis.

Paraplegia following abdominal aortic aneurysm surgery has been well described. We present the first report of a patient who developed spontaneous paraplegia in association with an abdominal aortic aneurysm.

\section{Case report}

A 65-year-old medical practitioner presented with sudden onset of weakness and paraesthesiae in both legs. He had been suffering from low back pain and paraesthesiae in his legs for some years, which had been attributed to crush fractures of his lumbar vertebrae following a parachuting accident. Although these symptoms were initially mild, they had become more troublesome a few weeks prior to presentation. He gave no history suggestive of occlusive peripheral vascular disease, but had, however, suffered a myocardial infarction 12 months previously and was under treatment for hypertension.

On admission his general condition was good with a pulse rate of 72 per minute and blood pressure of $110 / 80 \mathrm{~mm} / \mathrm{Hg}$. Abdominal palpation revealed a large abdominal aortic aneurysm.

He was anaesthetic to pin-prick below the level of T10, but dorsal column function was preserved, and he had a complete flaccid muscle paralysis (Grade 0 on the Oxford Scale) below the level of L1. X-rays of his abdomen and lumbar spine were carried out. These revealed a large abdominal aortic aneurysm. There was loss of height of L1 and T12. These appeared slightly radiolucent although there were overlying bowel gas shadows. Initial treatment was routine paraplegic care while he was prepared for elective resection of the aortic aneurysm. During this period, there was patchy improvement in muscle function in both limbs to power of grade 2 to 4 in all lower limb muscle groups except left hip flexors which had not recovered (Grade 0). At operation 1 week after 
admission, an $11.5 \mathrm{~cm}$ diameter aortic aneurysm was found which extended from just below the renal arteries to the aortic bifurcation. Copious clot was removed on opening the aneurysm and a tube graft anastomosed end-to-end to the infra renal aorta and to the bifurcation. He made a rapid and uneventful post-operative recovery and 2 weeks after his operation he was transferred to the Regional Spinal Injuries Unit for further rehabilitation. Eighteen months following his operation, he made a virtually complete neurological recovery.

\section{Discussion}

Paraplegia following aortic surgery is rare, but well documented (Szilagyi et al., 1978). To our knowledge there have been no reports of an otherwise asymptomatic infrarenal aortic aneurysm presenting with paraplegia. One would expect that as aortic aneurysmal disease is relatively common, this complication would have been reported previously. The explanation for this probably lies in the anatomical variations in origin of blood supply to the spinal cord. The anterior spinal artery is the most important source, supplying the anterior two thirds of the cord. In the majority of subjects, the anterior spinal artery supplying the lower thoracic and lumbar cord is derived from the arteria radicularis magna (ARM), the origin of which has been described as arising from the aorta between T8 and L4 (Suh et al., 1939). A low lumbar origin of the ARM is rare. We speculate that this patient had a low origin of the ARM and that deposition of thrombus or embolisation of sac contents occluded this vessel. Collateral supply through thoracic and sacral radicular arteries may then have been responsible for revascularisation of the cord and the subsequent neurological recovery.

\section{References}

Suh TH, AleXander L 1939 Vascular system of the human spinal cord. Archives of Neurology and Psychiatry 41:659-687.

Szilagyi DE, Hageman JH, Smith RF, Elliot JP 1978 Spinal cord damage in surgery of the abdominal aorta Surgery 83:38-56.

Williams AND WaRWICK Grays Anatomy 36 Ed. 1980 Churchill Livingstone, p. 896. 